\title{
A APLICAÇÃO DA POLÍTICA NACIONAL DE EDUCAÇÃO AMBIENTAL NA MODALIDADE DE EDUCAÇÃO DE JOVENS E ADULTOS DO IFBA
}

\author{
Bruno Britto de Miranda ${ }^{1}$ \\ Christiana Cabicieri Profice ${ }^{2}$ \\ Socrates Jacobo Moquete Guzman ${ }^{3}$
}

Resumo: A EA no contexto escolar objetiva abrir espaços para a construção de conhecimentos e para a articulação de saberes, possibilitando a formação de indivíduos que sejam partícipes na construção de uma sociedade sustentável, socialmente justa e ecologicamente equilibrada. Educar ambientalmente os sujeitos requer o envolvimento de um conjunto de atores sociais e de organização que contemplem ações alternativas ao modelo hegemônico de desenvolvimento, com ênfase na sustentabilidade socioambiental. Nesse contexto decidimos investigar o curso de Informática do PROEJA do Campus de Vitória da Conquista - BA e analisar se o mesmo atende a PNEA e o quanto as atitudes cotidianas dos professores alcança este público tão peculiar que é a modalidade EJA.

Palavras-chave: Educação de Jovens e Adultos; Educação Ambiental; PNEA; PROEJA.

\footnotetext{
${ }^{1}$ Instituto Federal de Educação, Ciência e Tecnologia da Bahia: E-mail: bbmiranda13@gmail.com

${ }^{2}$ Universidade Estadual de Santa Cruz: E-mail: ccprofice@uesc.br

${ }^{3}$ Universidade Estadual de Santa Cruz,: E-mail: socratesmoquete@gmail.com
} 


\section{Introdução}

A Educação Ambiental (EA) surge como uma importante estratégia de prevenção e resolução de problemas ambientais sejam eles locais como a poluição de um rio e a destinação do lixo de uma cidade ou mais amplos como o aquecimento global. Educar as pessoas e as gerações para novas atitudes e comportamentos em relação ao meio ambiente, esta é a tarefa da $E A$, que deve ser o mais precoce possível, contínua, formal e informal. Chegamos mesmo a concluir que qualquer educação hoje deve ser ambiental, comprometida com a sustentabilidade, em suas dimensões ecológicas, sociais e econômicas. Assim todos os educadores também devem ser ambientais, independente de sua formação disciplinar. As disciplinas, aliás, devem se relacionar continuamente, romper as fronteiras que as separam e impedem sua comunicação.

O lastro da EA não se restringe apenas ao conhecimento científico, mas o faz dialogar com outras formas de conhecimento como o das comunidades tradicionais e o filosófico. Apesar de termos atualmente referências bem claras sobre como a EA deva ser ainda nos encontramos distantes de sua efetivação plena, por algumas razões que serão abordadas nesse trabalho. Como veremos, as políticas públicas e diretrizes educacionais atuais constituem um verdadeiro avanço em relação às anteriores, sobretudo no que se refere aos temas ambientais, com especial atenção a um dos problemas ambientais mais viscerais de nossa história humana, a desigualdade social. Fonte de desequilíbrio entre as pessoas e também com os ambientes naturais, as inequidades sociais parecem ser a mais importante chaga a ser combatida na batalha pela sustentabilidade.

Entre as mazelas da desigualdade a falta de acesso à educação e/ou a sua baixa qualidade impedem a ruptura do ciclo de poder que mantém grande parte das pessoas do planeta, especialmente os mais jovens, em situação de risco pessoal e social. A EA também vem com a tarefa de combater as desigualdades sociais, dando oportunidades para aqueles que são tradicionalmente excluídos se tornarem protagonistas críticos de suas realidades e agentes multiplicadores da perspectiva da sustentabilidade. Aos educadores, que vem de uma época em que o tema ambiental apenas se enunciava e que foram formados conforme suas disciplinas específicas, resta a tarefa de transformar sua prática educativa de modo a incorporar os temas ambientais, e não apenas isso, a trabalhar ativamente para a formação de cidadãos ambientalmente sensíveis e ativos.

Temos diante de nós gerações que precisam pensar de um modo diferente sobre o meio ambiente, é nelas que depositamos nossas expectativas de um planeta mais equilibrado e sustentável. Os jovens, especialmente, são os próximos a definirem os rumos da sociedade, está na mão deles a missão de realizar algo melhor do que as gerações que os precederam. Porém, como revelam os dados fornecidos pelo IBGE (2013), 20\% dos jovens de 15 a 29 anos de idade não frequentam a escola nem trabalhavam. Neste trabalho tratamos de forma concisa desse histórico, por meio da análise das políticas Revbea, São Paulo, V. 10, N 1: 257-280, 2015. 
públicas voltadas aos jovens, sobretudo para aqueles trabalhadores, que foram de algum modo excluídos das modalidades regulares de ensino. O caráter profissionalizante de educação voltada para a juventude também é objeto de nossa reflexão, diante de propostas de formação que reproduziam as desigualdades sociais, pelo reforço da separação entre trabalho manual e intelectual. Neste quadro então, como acontece a EA? Como ela está presente nas políticas públicas de educação profissionalizante voltadas aos jovens e adultos? Como os educadores desta modalidade de ensino se posicionam diante da demanda em efetivar uma EA crítica sem que tenham sido capacitados especificamente para esta tarefa? Como a EA definida em um plano nacional (PNEA) e recomendada pelas políticas públicas e diretrizes educacionais se encarna nas instituições de ensino profissionalizante voltadas para os jovens?

Veremos que a Educação de Jovens e Adultos (EJA) no Brasil, como modalidade de ensino, é marcada por políticas públicas descontinuadas e insuficientes para dar conta das demandas sociais e desse modo garantir 0 direito à educação tal como foi estabelecido pela Constituição Federal de 1988,

O dever do Estado com a educação será efetivado mediante garantia de: I - ensino fundamental, obrigatório e gratuito, assegurada, inclusive, sua oferta gratuita para todos os que a ele não tiveram acesso na idade própria (BRASIL,1988, s/p).

Desde o início da história da educação brasileira existe uma preocupação com os jovens e adultos que por alguma razão não conseguiram concluir sua escolarização no sistema regular. Como veremos, muitas políticas públicas foram formuladas e implementadas para atender a esta parcela da população, contudo, muitas delas são conduzidas de modo parcial e limitadas, sendo muitas vezes modificadas ou revogadas de acordo com os interesses de consecutivos programas de governo.

O Programa Nacional de Integração da Educação Profissional com a Educação Básica na Modalidade de Educação de Jovens e Adultos/PROEJA lançado em 2005 visa criar oportunidades educativas aos jovens e adultos que foram impossibilitados de continuar seus estudos, ao mesmo tempo em que pretende prepará-los para o mercado de trabalho no qual, na maioria das vezes, já se encontram inseridos. O documento argumenta a favor da

Urgência de tratamento não fragmentado, mas totalizante e sistêmico, sem o que se corre o risco de manter invisibilizada socialmente essa população, frente ao sistema escolar e, seguramente, no mundo do trabalho formal, exigente de certificações e comprovações de escolaridade formal (BRASIL, 2007, p.18). 
Esta nova modalidade de ensino na rede federal colocou-se como desafio para uma construção curricular que integre a educação básica, a profissionalizante e a EJA, o que inevitavelmente exigiu mudanças e adaptações por parte dos técnicos e docentes das instituições públicas de ensino médio profissionalizante. O desafio maior consiste em elaborar uma proposta curricular que contemple o trabalho como princípio educativo, a partir de uma sintonia entre professores e gestores, que buscarão entender o mundo do trabalho a partir das diversas disciplinas.

Outro desafio colocado pela política do PROEJA é a necessária inclusão da Educação Ambiental (EA) em suas referências curriculares, conforme previsto em outra política federal de educação, a Politica Nacional de Educação Ambiental (PNEA). A integração do PNEA pela PROEJA implica em uma abordagem de educação própria da EA, como veremos adiante.

Conforme a PNEA (BRASIL, 1999), a abordagem da EA no contexto escolar objetiva abrir espaços para a construção de conhecimentos e para a articulação de saberes, possibilitando a formação de indivíduos que sejam partícipes na construção de uma sociedade sustentável, socialmente justa e ecologicamente equilibrada. Nesse sentido, educar ambientalmente os sujeitos requer o envolvimento de um conjunto de atores sociais e de formas de organização que contemplem ações alternativas ao modelo hegemônico de desenvolvimento, com ênfase na sustentabilidade socioambiental.

Assim, diante desta interface de políticas de educação, o estudo consonância da PNEA no PROEJA é relevante no sentido de elucidar congruências e afastamentos entre as duas diretivas. Com o objetivo de refletir sobre o papel e a relevância da EA na EJA, sobretudo em sua modalidade profissionalizante, este trabalho visa estabelecer um diálogo entre o PNEA e o curso de informática do PROEJA do Instituto Federal de Educação, Ciência e Tecnologia do Campus de Vitória da Conquista, no estado da Bahia. Nossa intenção é apreciar em que medida a EA, pode contribuir para a formação de indivíduos ambientalmente mais críticos e capazes de interferir na sua realidade socioambiental.

Analisamos as questões ambientais presentes no documento base do PROEJA e no Projeto Pedagógico de Curso (PPC), buscando suas a suas consonâncias com a PNEA; apreciamos as ementas na matriz curricular do Projeto Pedagógico de Curso (PPC) da Modalidade EJA e identificados quais elementos atendiam ao PNEA. Ao mesmo tempo pudemos caracterizar como a abordagem ambiental vem sendo estabelecida pelo corpo docente da modalidade EJA no IFBA de Vitória da Conquista por meio da aplicação de um questionário. 


\section{Formação Profissional No Brasil}

No Brasil a educação profissional nasce formalmente no inicio do século $X X$, em um contexto diferente do atual, caracterizado por diretrizes que visavam preparar as camadas sociais excluídas para funções e tarefas de ordem mais práticas e, portanto, menos valorizadas do que aquelas intelectuais (FONSECA, 1961). Como veremos, esta foi a herança de um processo colonizador que colocava de um lado as elites preparadas para o pensar e elaborar criativo e do outro os setores populares, compostos em grande parte por índios, negros e mestiços (PRADO JR., 2011).

Atualmente temos políticas específicas e de cotas para que os negros e índios possam ter melhores oportunidades de acesso às escolas destinadas ao ensino profissional, mas nos tempos mais remotos da colonização os mesmos foram os primeiros aprendizes de ofícios, e "[...] habituou-se o povo de nossa terra a ver aquela forma de ensino como destinada somente a elementos das mais baixas categorias sociais" (FONSECA, 1961, p.18). Desse modo fortaleceuse uma diferença qualitativa entre trabalho manual e trabalho intelectual no âmbito das políticas públicas educacionais brasileiras, que termina por reforçar as desigualdades sociais. Sendo os ofícios do trabalho pesado e dos manuais destinados aos deserdados da sorte, os trabalhadores livres ficaram impedidos de exercer certas profissões consideradas mais intelectuais e, por sua vez, os filhos de colonos permanecem afastados de qualquer tipo de trabalho físico ou manual. Fonseca (1961) salienta o quão inerente era este fato, assinalando que para desempenhar funções públicas uma condição era que nunca o candidato tivesse trabalhado manualmente.

Com a corrida do ouro chegando a Minas Gerais no século XVII surgiu a necessidade da criação das casas de Fundição e de Moeda, e assim também de uma mão de obra qualificada. Porém, essa mão de obra se diferenciava das realizadas nos engenhos de açúcar, pois se destinava apenas aos filhos da própria casa, ou seja, os homens brancos. Os trabalhadores dos engenhos realizavam suas atividades de forma pouco especializada, não necessitando deste modo provar seus conhecimentos práticos, enquanto que os filhos brancos das casas de Fundição e de Moeda necessitavam comprovar suas habilidades no fim de um período de cinco a seis anos a uma banca examinadora e recebendo ao final, se aprovados, uma certidão de aprovação.

No mesmo ano de 1763 em que o Brasil subia a categoria de Vice-Reino e o Rio de Janeiro passava a ser a sua capital, D. Antônio Álvaro da Cunha, que veio como primeiro Vice-Rei, fundou o Arsenal de Marinha do Rio de onde posteriormente nasceram os Centros de Aprendizagem de Ofícios nos Arsenais da Marinha no Brasil. Os operários destes Centros de Aprendizagens eram operários especializados de Portugal e, eventualmente, a patrulha do Arsenal recrutava aqueles que vagavam após o toque de recolher. "Algumas vezes a necessidade de pessoal era tanta, que se recorria ao Chefe de Polícia, pedindoIhe que enviasse, dos seus presos, aqueles que estivessem em condições de produzir algum trabalho profissional' (FONSECA, 1961, p. 82). Um componente importante do enfraquecimento do desenvolvimento tecnológico do Brasil veio

revista brasileira educação ambiental 
com a proibição da existência de fábricas em 1785, uma tentativa de impedir a autonomia da colônia e reforçar sua mera condição de fornecedora de recursos e de força manual.

Ainda conforme Fonseca (1961) é apenas a partir de meados do século XIX que as indústrias se estabeleceram e iniciaram seus ensinos destinados inicialmente aos silvícolas, posteriormente incluindo os escravos, em seguida também os órfãos e mendigos. Posteriormente deu-se a criação, por D. Pedro II, do Imperial Instituto dos Surdos-Mudos, que se destinava ao ensino de ofícios: os cegos aprendiam tipografia e encadernação e os surdos-mudos, sapataria, encadernação, pautação e douração. Para confirmar que o ensino continuava a fazer parte apenas da classe dos desvalidos, foi instituído o Decreto ํㅜ 1.331-A de 01 de fevereiro de 1854 que reformava a instrução primária e secundária do Município Neutro, e que continha medidas para os menores abandonados, criando para eles asilos, onde receberiam a instrução de $1^{\circ}$ grau e posteriormente seriam enviados às oficinas públicas ou particulares para aprenderem um ofício.

Com o fim da escravidão e a proclamação da República em 1889, nascia a perspectiva de alterar o panorama em relação ao ensino de ofícios. Conforme Romanelli (1980), na Constituição da República de 1891, foi instituído o sistema federativo de governo, consagrando também a descentralização do ensino e a dualidade de sistemas, delegando à União a criação e o controle do ensino superior e o ensino secundário; aos Estados coube criar e controlar o ensino primário e o ensino profissional. Nesta direção, o Presidente do Estado do Rio de Janeiro, como eram chamados os governadores na época, Nilo Peçanha, iniciou no Brasil o ensino técnico por meio do Decreto $n^{\circ} 787$, de 11 de setembro de 1906, criando quatro escolas profissionais naquela unidade federativa: Campos, Petrópolis, Niterói, e Paraíba do Sul, sendo as três primeiras, para o ensino de ofícios e a última à aprendizagem agrícola. Como presidente do Brasil em 1909 assina o Decreto no 7.566, criando, inicialmente em diferentes unidades federativas, sob a jurisdição do Ministério dos Negócios da Agricultura, Indústria e Comércio, dezenove "Escolas de Aprendizes Artífices", destinadas ao ensino profissional, primário e gratuito (BRASIL, 2011a). Porém, seu funcionamento foi precário tanto no que tange as instalações das escolas como na formação de professores atuantes. Como destacou Fonseca (1961), a eficiência não poderia deixar de ser senão pequena, mas a causa principal do baixo rendimento era a falta completa de professores e mestres especializados.

Ainda em 1941 uma série de leis conhecida como "Reforma Capanema" remodelou todo ensino do país, com mudanças do tipo: o ensino profissional passou a ser considerado de nível médio e o ingresso nas escolas industriais exigiam exames admissionais. Em 1942 temos uma nova mudança na nomenclatura e na sua estruturação com o Decreto $n^{\circ} 4.127$, as Escolas de Aprendizes e Artífices passam a se chamar Escolas Industriais e Técnicas, passando a oferecer a formação profissional em nível equivalente ao do secundário. Paralelamente é criado ainda em 1942 o Serviço Nacional de Aprendizagem dos Industriários (SENAI), organizado e dirigido pela Confederação Nacional da Indústria.

Revbea, São Paulo, V. 10, Nº 1: 257-280, 2015. 
A Lei de Diretrizes e Bases da Educação Brasileira (LDB), №. 5.692, de 11 de agosto de 1971, no seu Art. 5을 inciso $2^{\circ}$, torna, de maneira compulsória, técnico-profissional, todo currículo do segundo grau. Formar técnicos sob o regime da urgência nesse tempo de milagre do desenvolvimento, fez com que as Escolas Técnicas Federais crescessem expressivamente o número de matrículas e implantação de novos cursos técnicos. Em 1978 a Lei $n^{\circ} 6.545$ transforma três Escolas Técnicas Federais em Centros Federais de Educação Tecnológica (CEFETs).

Em 1994 as Escolas Técnicas Federais e as Escolas Agrotécnicas Federais são transformadas gradativamente pela Lei no 8.948 , de 8 de dezembro em Centros Federais de Educação Tecnológica, mediante decreto específico para cada Centro. De 1909 a 2002 foram construídas 140 unidades, melhor configurando a Rede Federal de Educação Profissional e Tecnológica brasileira. Em 2005, com a publicação da Lei 11.195, ocorre o lançamento da primeira fase do Plano de Expansão da Rede Federal de Educação Profissional e Tecnológica, com a construção de 64 novas unidades de ensino. Em 2007 há o lançamento da segunda fase de Expansão, tendo como meta entregar à população mais 150 novas unidades, perfazendo um total de 354 unidades, até o final de 2010, sintonizados com as necessidades de desenvolvimento local e regional (BRASIL, 2011a, p. 6).

Desde 29 de dezembro de 2008, 31 centros federais de educação tecnológica, 75 unidades descentralizadas de ensino (Uneds), 39 escolas agrotécnicas, 7 escolas técnicas federais e 8 escolas vinculadas a universidades deixaram de existir para formar os Institutos Federais de Educação, Ciência e Tecnologia (IF's) (BRASIL, 2011a, p. 6). É neste enquadramento que se encontra o IFBA de Vitória da Conquista, no estado da Bahia. Vale destacar que a falta de qualificação docente para o ensino profissionalizante é uma problemática que persiste até hoje, apesar das expansões e do aumento no número de mestres e doutores. Conforme recente auditoria do Tribunal de Contas da União (TCU) "na rede de institutos federais de educação técnica mostra que faltam quase 8 mil professores, o equivalente a $20 \%$ dos profissionais necessários. $O$ déficit atinge toda a rede de 442 campus em funcionamento no País." (SALDAÑA, 2013, p.1).

\section{A Modalidade Educação de Jovens e Adultos/EJA}

São esses Institutos Federais de Educação, Ciência e Tecnologia que tem a missão de agregar o jovem e o adulto em uma modalidade intermediária de ensino fora dos padrões educacionais regulares. Como vimos, até a primeira metade do século $X X$ não havia nenhuma atenção governamental devida a essa parcela da população que estava às margens do ensino regular. Nesta direção, foi apenas a partir da segunda metade deste mesmo século que foi se formatando um pensamento pedagógico e, consequentemente, politicas públicas voltadas para a modalidade EJA. Criou-se então em 15 de dezembro de 1967 com a Lei 5.379 o Movimento Brasileiro de Alfabetização (MOBRAL), que tinha o objetivo de alfabetizar funcionalmente e promover uma educação continuada de adolescentes e adultos, ficando restrita à apreensão da

revista brasileira educação ambiental 
habilidade de ler e escrever, sem haver a compreensão contextualizada dos signos. No final da década de 70 o MOBRAL passou por diversas reformulações para garantir sua permanência, sobretudo com a promulgação da lei de Diretrizes e Bases da Educação Nacional, Lei ํㅡ 5692/71 que, em seu Capitulo IV, regulamentou o ensino supletivo, que tinha por finalidade suprir a escolarização regular para os adolescentes e adultos que não a tenham seguido ou concluído na idade própria. Desse modo, "o Ensino Supletivo se propunha a recuperar o atraso, reciclar o presente, formando uma mão-de-obra que contribuísse no esforço para o desenvolvimento nacional, através de um novo modelo de escola" (HADDAD; DI PIERRO, 2000, p.117).

A década de 1980 se inicia com a extinção do MOBRAL e com a criação de um novo programa, a Fundação Nacional para Educação de Jovens e Adultos (EDUCAR), conhecida como Fundação Educar, criada em 1985. Para fortalecer ainda mais essa cobrança no atendimento ao publico EJA. Mesmo tendo sido considerada como uma continuidade do MOBRAL à Fundação Educar coube cuidar da formação e do aperfeiçoamento dos educadores, produzir o material didático, promover o atendimento para os educandos jovens e adultos nas séries iniciais do ensino de $1^{\circ} \mathrm{grau}$, bem como fazer a avaliação das atividades e supervisionar o desenvolvimento do trabalho, ressaltando que em 1986 a Fundação Educar passou por mudanças significativas tendo reformuladas as suas diretrizes político-pedagógicas.

Dez anos depois, em 1996, para atender também a educação de Jovens e Adultos, surge a Lei de Diretrizes e Bases da Educação Nacional a LDB 9.394/96, que trata da educação de jovens e adultos no Título V, capítulo II como modalidade da educação básica, superando sua dimensão de ensino supletivo, regulamentando sua oferta a todos aqueles que não tiveram acesso ou não concluíram o ensino fundamental.

Porém, a nova LDB ainda pecava em não contemplar algumas necessidades básicas desse publico tão peculiar como descreve bem Haddad,

Foram deixados de lado vários aspectos, como por exemplo: escolas próximas do trabalho e da residência; criação de condições próprias para a recepção de teleducação em empresas com mais de cem funcionários; apoio de programas de alimentação, saúde, material escolar e transporte, implementação de formas e modalidades diversas que contemplem os estudantes nas diferentes regiões do país [...] (HADDAD, 2007, p. 9).

Desde 2003, o MEC conduz o Programa Brasil Alfabetizado (PBA), voltado para a alfabetização de jovens, adultos e idosos, que tem como objetivo promover a superação do analfabetismo entre jovens com 15 anos ou mais, adultos e idosos e contribuir para a universalização do ensino fundamental no Brasil. Sua concepção reconhece a educação como direito humano e a oferta pública da alfabetização como porta de entrada para a educação e a escolarização das pessoas ao longo de toda a vida. Em 20060 Revbea, São Paulo, V. 10, Nº 1: 257-280, 2015. 
Ministério da Educação aprovou a criação do Fundo de Desenvolvimento da Educação Básica (FUNDEB), passando então, todas as modalidades de ensino, inclusive a Educação de Jovens e Adultos, a fazer parte dos recursos financeiros destinados à educação.

Nesse contexto, para contemplar mais uma vez a escolarização de jovens e adultos foi implementado no Brasil o Programa de Integração da Educação Profissional ao Ensino Médio na Modalidade de Educação de Jovens e Adultos (PROEJA). O PROEJA foi criado através do Decreto 5.478 de 24 de junho de 2005, e tinha sua nomenclatura como: Programa de Integração da Educação Profissional ao Ensino Médio na Modalidade Educação de Jovens e Adultos, implantado na Rede Federal de Educação Profissional e Tecnológica, sendo que algumas destas Instituições Federais já praticavam ações no âmbito da educação profissional de jovens e adultos.

Sentindo-se a necessidade de maior abrangência do Programa, o Decreto 5.840 de 13 de julho de 2006 revogou o anterior, passando a denominar-se PROEJA como Programa Nacional de Integração da Educação Profissional com a Educação Básica na Modalidade de Educação de Jovens e Adultos, possibilitando sua adotação também em instituições de ensino Estaduais e Municipais, assim como em entidades nacionais de serviço social, aprendizagem e formação profissional (instituições do sistema "S" - SESI, SESC, SENAI, SENAC). "[...] tendo como horizonte a universalização da educação básica, aliada à formação para o mundo do trabalho, com acolhimento específico a jovens e adultos com trajetórias escolares descontínuas" (BRASIL, 2007, p. 11).

Este nível de ensino, em muitas administrações Municipais, Estaduais e Federais, ainda hoje é tratado simplesmente como um ensino fundamental e médio normal, mudando apenas o turno das aulas. Os profissionais que atuam nestes, na maioria das vezes, são os mesmos que atuam com alunos da EJA. "Podemos, simplesmente, aproveitar os professores de $1^{\underline{a}}$ a $4^{\underline{a}}$, e de $5^{\underline{a}}$ a $8^{\text {a }}$, dando a eles certa reciclagem para, em vez de falarem criança ou menino, falarem jovem ou adulto e talvez, resolvamos esse problema" (ARROYO, 2006, p. 20, grifo do autor).

Para atender a este novo programa educacional requisitado pelo governo federal e à grande parcela de jovens da região de Vitória da Conquista, o Instituto Federal de Educação, Ciência e Tecnologia da Bahia (IFBA), campus de Vitória da Conquista apresentou para a comunidade no ano de 2006 o Curso Profissional Técnico de Nível Médio na Área de Informática na Modalidade de Educação Para Jovens e Adultos, articulado de forma integrada, organizado em seis semestres letivos (três anos) com Estágio Curricular Obrigatório previsto, para a obtenção da habilitação de Técnico de Nível Médio na Área de Informática, com qualificação de Mantenedor de Computadores e Redes. Este curso visa, propiciar a formação geral dos estudantes, conciliando fundamentos científicos e tecnológicos que relacionem a prática e a teoria, através das diversas disciplinas ministradas no decorrer dos seis semestres e do Estágio Curricular Obrigatório. 


\section{Reflexões sobre a Educação Ambiental no PROEJA}

Nas décadas de 1950 e 1960, antecedendo a crise ambiental da década de 1970, episódios como a contaminação do ar em Londres e Nova York, entre 1952 e 1960, os casos fatais de intoxicação com mercúrio em Minamata e Niigata, entre 1953 e 1965, a diminuição da vida aquática em alguns dos Grandes Lagos norte-americanos, a morte de aves provocada pelos efeitos secundários imprevistos do diclorodifeniltricloroetano (DDT) e outros pesticidas, receberam ampla publicidade, fazendo com que países desenvolvidos temessem que a contaminação já estivesse pondo em perigo o futuro do homem. Ainda não se falava de Educação Ambiental (EA), mas os problemas ambientais já demonstravam a irracionalidade do modelo de desenvolvimento capitalista e a necessidade de alertar a população e estimular atitudes pró-ambientais. Os movimentos de defesa do meio ambiente e da ecologia, ganharam força após a publicação do livro "Primavera Silenciosa", em 1962, da americana Raquel Carson, que denunciava dentre outras coisas o DDT como vilão de forte potencial para ocasionar câncer em seres humanos e interferir na vida animal, causando, por exemplo, o aumento de mortalidade entre os insetos e pássaros. Após essa publicação, de repercussão mundial, os militantes ambientalistas e a Organização das Nações Unidas (ONU) realizaram diversos eventos internacionais abordando a questão da preservação e da Educação Ambiental.

Desde então, a EA se desenvolveu assumindo alguns princípios que estão em estabelecidos no nível conceitual, mas que ainda encontram dificuldades de aplicação. A EA deve ser uma educação ininterrupta, continuada, para todos, ao longo de toda a vida, sendo a escola um espaço privilegiado para sua efetivação, sobretudo entre crianças e jovens. A instituição educativa é, portanto, o lugar de excelência para que a educação estimule a promoção e criação de saberes, sensibilidades, valores e atitudes críticas e positivas em relação ao meio ambiente. Diante dessa demanda cabe à escola e seus gestores trabalharem em conjunto para que o curso possa compreender o que de fato é a EA e debruçar-se sobre o currículo no intuito de incluir da melhor forma possível o meio ambiente como tema transversal. Como destaca Gregório e Lisovski (2011), a inclusão da EA na EJA pode contribuir para que o aluno que também é um cidadão, desenvolva uma consciência ambiental critica, tornando-os iguais na autonomia aqueles que já eram iguais na necessidade. $\mathrm{E}$ a escola tem um papel fundamental neste aspecto,

A escola é, portanto uma dos mais precisos meios veiculares de comunicação envolvidos na educação. E melhor ainda dizendo, dentro do processo da EJA, torna-se com certeza, um precioso aliado. É o genitor de um ser que se forma para exercer sua cidadania, o ser cidadão, aquele que desprendido da insignificância que às vezes se encontra, enquanto sentimento, possa sentir o desejo e a necessidade de contribuir cada vez mais para a reelaboração e condução da história tanto do grupo social que está inserido quanto de si mesmo. (SOUZA; OLIVEIRA, 2012, p. 2).

Revbea, São Paulo, V. 10, N 1: 257-280, 2015. 
Se a escola se omite no seu papel de formador do cidadão critico ambientalmente e não consegue trabalhar em um currículo equitativo, dificilmente os professores conseguirão exercer de uma forma efetiva a Educação Ambiental nas suas disciplinas, principalmente quando se trata da EJA.

Essa discussão remete a um segundo aspecto que evidencia a essencialidade da dimensão ambiental na Educação de Jovens e Adultos. Trata-se do hábito em muitas escolas de não trabalhar a dimensão ambiental nas turmas de EJA. Sendo assim, os jovens e adultos populares ficam privados da participação no debate ambiental, apesar de que a escola não é o único espaço sócio-educativo no qual se dá essa reflexão. (REZENDE, 2011, p.8).

Conforme Gonçalves e Sá, Pereira e Moura (2012), um dos papéis da escola é levar alunos aos que ingressaram tardiamente na vida escolar, novas visões de mundo, onde a metodologia aplicada deve se adequar a realidade dos mesmos, facilitando sua compreensão em relação aos direitos e deveres do ser cidadão no contexto ambiental. Quando se trata de uma metodologia aplicada à Educação Ambiental segundo Gregório e Lisovski (2011, p. 8), "os professores devem ter o cuidado de não passar uma visão simplista e ingênua de ambiente".

O Plano Nacional de Educação Ambiental (PNEA), lançado em 1999, deixa claro, logo no art. $2^{\circ}$ do primeiro capitulo, a importância do processo educativo em caráter formal ou informal, como componente essencial e permanente da educação nacional. Conforme argumenta Reigota "é consenso entre a comunidade internacional que a Educação Ambiental deve estar presente em todos os espaços que educam o cidadão" (2009, pág.39). Trata-se de fomentar uma mudança de atitude ambiental. Por isso a EA deve estar presente em todos os níveis de ensino como descrito no art. $9^{\circ}$ da PNEA, incluindo assim o PROEJA do IFBA de Vitória da Conquista, por se tratar de uma modalidade de educação de jovens e adultos. A própria composição heterogênea do público de PROEJA se encontra refletida na PNEA que prevê no VIII do art. $4^{\circ} \mathrm{o}$ reconhecimento e respeito à pluralidade e à diversidade individual e cultural. Aqui, não estamos falando somente de alunos do ensino médio com idades regulares, e sim, estudantes com as idades mais variadas possíveis, variando de 18 a 60 anos, que possuem histórias de vida das mais diversas, experiências em trabalhos formais e informais, e uma bagagem cultural que nenhuma escola precisou fornecer, mas que já vem a tiracolo e precisa ser aproveitada para que experiências de EA ou de qualquer tipo de ensino possa ser desenvolvidas. A EA parte do respeito à diversidade, promovendo um posicionamento crítico diante da realidade e comportamentos ambientalmente corretos na relação sociedade e natureza, além do 
compromisso com a melhoria de vida presente e futura no planeta como destaca Reigota (2006)

\begin{abstract}
A Educação Ambiental deve procurar favorecer e estimular possibilidades de se estabelecer coletivamente uma "nova aliança" (entre os seres humanos e a natureza e entre nós mesmos) que possibilite a todas as espécies biológicas (inclusive a humana) a sua sobrevivência com dignidade (p.14).
\end{abstract}

Outro item relevante da PNEA para nossa discussão se encontra no art. $8^{\circ}, \S 2^{\circ}$, inciso I e trata da incorporação da dimensão ambiental na formação, especialização e atualização dos educadores. Essa incorporação, se absorvida de forma eficaz pelas instituições de ensino torna os educadores não apenas especialistas em sua área de ensino, mas também preparados para a EA e para a aplicação de seus princípios na prática docente.

Um dos princípios básicos da EA que consta no art. $4^{\circ}$ inciso III, trata do "pluralismo de ideias e concepções pedagógicas, na perspectiva da inter, multi e transdisciplinaridade". Este princípio deixa claro o quanto a lei deseja que as disciplinas caminhem de mãos dadas para o bem comum nas relações entre natureza e ser humano, de uma forma que não restrinja apenas ao seu próprio conteúdo, mas que o tema ambiental permeie todas elas. Esta ideia de educação integral e não compartimentada, ainda que não vinculada ao tema ambiental, pode ser encontrada no documento base que rege o PROEJA:

Assim, uma das finalidades mais significativas dos cursos técnicos integrados no âmbito de uma política educacional pública deve ser a capacidade de proporcionar educação básica sólida, em vínculo estreito com a formação profissional, ou seja, a formação integral do educando (BRASIL, 2007, p.35, grifo nosso).

Reigota (2006) descreve algumas modalidades para a realização da $E A$, porém deixa claro que cada professor e professora adote a sua de acordo com as características de seus alunos e do contexto educativo em que se encontram. Os métodos são: "passivo (em que só professor fala), ativo (em que os alunos fazem experiências sobre o tema), descritivo (em que os alunos aprendem definição de conceitos e descrevem o que eles puderam observar, por exemplo, numa excursão) e analítico (em que os alunos completam sua descrição com dados e informações e respondem a uma série de questões sobre o tema). Os educadores também não podem perder de vista que seus alunos não chegam nas escolas sem uma visão ambiental, por mais limitada que ela seja. Ele já vem com imagens e valores acerca da temática ambiental, compartilhadas pelas pessoas de seu contexto sociocultural. O tema meio 
ambiente está incluído nas representações sociais que temos da realidade e foram descritas por Reigota (1995) da seguinte forma:

\begin{abstract}
Naturalista - meio ambiente voltado apenas a natureza, evidencia aspectos naturais, confundindo-se com conceitos ecológicos como de ecossistema. Inclui aspectos físicoquímicos, a fauna e a flora, mais exclui o ser humano deste contexto. O ser humano é um observador externo; Globalizante - o meio ambiente é caracterizado como as relações entre a natureza e a sociedade. Engloba aspectos naturais políticos, sociais, econômicos, filosóficos e culturais. O ser humano é compreendido como ser social que vive em comunidade; Antropocêntrica - o meio ambiente é reconhecido pelos seus recursos naturais, mas são de utilidade para a sobrevivência do homem.
\end{abstract}

Desse modo para atingir de uma forma mais eficiente o aluno, a EA tem que permear todas as disciplinas independentes de suas características peculiares ou não, mesmo diante de uma matriz curricular formada com as mais diversas disciplinas como é o caso do curso pesquisado, de algum modo o professor tem que achar um meio para encaixa-la no seu plano de ensino em algum momento. Como destacam Gregório e Lisovski (2011, p. 8) "na EJA onde os alunos trazem consigo uma bagagem cultural é de extrema importância que a EA tome relevância e passe a fazer parte do cotidiano do educando, quebrando paradigmas já existentes com relação ao termo Meio Ambiente". De certo modo quebrar paradigmas já faz parte da vida desses educandos, como destacado anteriormente, são jovens e adultos que buscam vencer barreiras ao retornarem para a escola, seja motivado por razões de ordem pessoal ou por exigência do mercado de trabalho.

De todo modo são pessoas que buscam superar preconceitos e discriminações em prol dos seus anseios e desejos, que lutam com o fantasma da evasão que os assombra constantemente, que combatem o analfabetismo que Ihes acompanha diariamente e que os amarra em correntes invisíveis do preconceito e das dificuldades. Segundo Guimarães e seus colaboradores (2009, p.5),"o trabalho da EJA precisa ser direcionado a ultrapassar as barreiras da educação passando a incorporar a dimensão ambiental no currículo [possibilitando] que o aluno reflita de forma crítica a sua relação com a natureza, podendo contribuir para mudança de comportamento e atitudes".

Quando revemos os princípios que regem a $E A$, verificamos que a Educação Ambiental formal deve ser inserida de forma transversal, ou seja, não inclusa como uma disciplina em si, mais permeando todas as disciplinas de uma forma interdisciplinar ou não, segundo Gonçalves e Sá, Pereira e Moura (2012, p. 75), "é nesse contexto que as reflexões sobre as questões ambientais devem ser inseridas, uma vez que a transversalidade da Educação Ambiental 
visa mudar os valores nas relações entre os seres humanos e destes com o mundo que os cerca".

Porém nem todo currículo é formulado de modo que as disciplinas trabalhem de uma forma articulada e efetue a inclusão do tema meio ambiente nas mesmas. O curso de informática do PROEJA do Instituto Federal de Educação, Ciência e Tecnologia do Campus de Vitória da Conquista, no estado da Bahia, opera conforme com um currículo transdisciplinar, ou seja, uma é constituído por diferentes disciplinas que envolvem assuntos especificamente técnicos da área de informática bem como os conteúdos comuns ao ensino médio. $\mathrm{E}$ são as disciplinas técnicas que colocam mais dificuldades para trabalhar a EA, pois muitas vezes os assuntos abordados em sala não facilitam a inclusão de uma perspectiva ambiental de forma imediata, forçando o professor a adaptações ou mesmo à desistência.

\section{Método, Procedimentos e Participantes}

O objetivo geral do estudo que apresentamos foi levantamento e análise da consonância entre o Programa Nacional de Integração da Educação Profissional com a Educação Básica na Modalidade de Educação de Jovens e Adultos do Instituto Federal da Bahia - Campus de Vitória da Conquista e a Política Nacional de Educação Ambiental. Para tal fim analisamos as dimensões ambientais presentes no documento base do PROEJA em relação à PNEA; avaliamos as ementas na matriz curricular do projeto de curso da modalidade EJA e suas formulações para atender o PNEA; e caracterizamos como a abordagem ambiental está sendo conduzida pelo corpo docente da modalidade EJA. O IFBA - Campus de Vitória da Conquista, atualmente é uma instituição estratégica no estado por sua localização geográfica, oferecendo para a sociedade local, do sudoeste da Bahia e mesmo para o norte de Minas Gerais cursos de educação tecnológica profissional em diversos níveis do sistema educacional, inclusive a Educação de Jovens e Adultos. Localizada em um bairro periférico da cidade chamado Vilas Serrana atende atualmente mais de mil estudantes em todos os níveis de ensino, percorrendo do básico ao superior.

Após extensa leitura da PNEA, do PPC e no Documento Base do PROEJA ensino médio foram destacados os pontos convergentes e divergentes nos referidos documentos, exemplificando trechos que se refiram, direta ou indiretamente, aos aspectos fundamentais da EA. Em seguida, foi aplicado um questionário entre os docentes do curso buscando detectar se a EA é por eles conduzida de acordo com a PNEA, bem como qual a compreensão dos docentes participantes acerca do tema pesquisado, e, sobretudo, de como atuam no intuito de agregar valores que permitam a construção de pessoas mais críticas ambientalmente, capazes de interferir de formas positivas no meio em que interagem. O questionário, além de coletar informações acerca dos dados pessoais e profissionais dos professores, investigou se há preocupação do com o ambiente e quais suas atitudes 
cotidianas para cuidar do mesmo. Buscamos também levantar seus conhecimentos prévios sobre o PROEJA e a PNEA, bem como acerca de sua aplicação na prática docente. Indagamos também acerca de sua participação em pesquisas de temática ambiental e se consideram relevante abordar o tema na sala de aula. A justificativa da importância do meio ambiente na sua prática docente bem como as atividades que eram propostas nesta direção também foram abordadas no questionário. Foi perguntado também qual era o espaço escolhido para a EA sugerindo como possibilidades os seguintes locais: Espaço Escolar; Comunidade Local; Áreas Preservadas; Outros.

Por fim buscamos apreciar os métodos adotados pelos docentes, utilizando a classificação de Reigota (1995) acima detalhada. O corpo docente do curso de informática do PROEJA é formado por professores oriundos não somente da cidade de Vitória da Conquista, mas também de locais diferentes do estado da Bahia e de Minas Gerais. Dos dezenove professores atuantes no semestre de 2013.2 que atendem cerca de sessenta alunos, somente treze se comprometeram a fazer parte da pesquisa, contudo, estamos cientes que o grupo de professores participantes é pequeno o que nos impede de avançar generalizações mais amplas, porém pudemos efetuar análise que julgamos relevantes para a nossa discussão.

\section{Resultados e Discussão}

Após a análise comparativa dos documentos pudemos concluir que 0 Documento Base do PROEJA e o PCC refletem grande parte das concepções do PNEA, ainda que não façam qualquer referência direta à EA. Identificamos nos dois documentos analisados nove questões ou concepções próprias da EA que se fazem sentir seja pela sua presença ou, ainda, como no caso da última, pela sua ausência. A primeira questão diz respeito à ausência literal do termo Educação Ambiental nos documentos analisados. Isto não significa que os documentos do PROEJA e do PCC sejam alienados ambientalmente, mas indica que neles o modelo de educação adotado não é necessariamente ambiental. Nesta direção, a segunda questão se refere ao enfoque humanista, holístico e democrático característico da EA.

Os documentos analisados comungam com o PNEA a concepção de um cidadão crítico e consciente, orientado por princípios equitativos. A terceira questão que destacamos se refere diretamente à relação das pessoas com a natureza, reforçando uma visão crítica dos impactos gerados pelas atividades humanas nos ambientes e demais seres e processos naturais. Aqui também encontramos consonância entre o PNEA e os demais documentos. A quarta questão que assinalamos diz respeito ao método de ensino que deve sempre atentar para a multi, inter e transdiciplinaridade. Este é um ponto em que realmente encontramos um acordo, a clareza da necessidade de uma relação de equilíbrio entre as disciplinas. O quinto aspecto que destacamos é a estreita vinculação entre ética, educação e trabalho também claramente explicitada em todos os documentos. A sexta questão diz respeito à garantia de continuidade

revista brasileira educação ambiental 
do processo educativo, assumindo o fracasso de políticas e práticas fragmentadas tão características do ensino brasileiro, seja em relação ao público jovem e adulto, seja em relação ao ensino profissionalizante.

A sétima questão decorre da anterior, sugerindo claramente, nos três documentos, a adoção de uma contínua avaliação crítica do processo educativo, marca própria da EA que encontramos também no PROEJA e no PCC do curso de informática do IFBA de Vitória da Conquista. Em oitavo lugar destacamos nos três documentos a importância concedida ao reconhecimento da pluralidade e diversidade cultural como base para o processo educativo. Contudo, uma nona questão muito relevante para a EA, a visão sistêmica do planeta, a consciência das interações entre distintas dimensões do meio ambiente e da articulação entre questões ambientais locais, regionais, nacionais e globais, não está explicitada nos demais documentos. Nem no documento base do PROEJA nem no PCC pudemos identificar a abordagem sistêmica de meio ambiente, abordagem crucial para a EA crítica tal como colocada no PNEA.

O que podemos concluir desta comparação entre o PNEA, o documento base do PROEJA e o PCC do curso de informática do IFBA de Vitória da Conquista é que grande parte dos princípios da EA são satisfatoriamente compartilhados. Porém, os dois últimos ainda não incorporaram as dimensões ecológicas em suas representações de meio ambiente, dado que este é concebido, prioritariamente, por seus aspectos sociais, culturais e econômicos. A natureza, componente indispensável de uma visão ecológica de meio ambiente, entra nesta concepção ambiental de modo pouco relevante, apenas como um fator a não ser negligenciado. Ou seja, tanto no documento base do PROEJA como no PCC do curso de informática do IFBA de Vitória da Conquista os aspectos humanos do ambiente, orientados por princípios éticos e humanistas estão no foco da ação educativa que pouco se volta para os seus aspectos naturais.

Em relação aos aspectos sociais e culturais da educação, inclusive da $E A$, os documentos do PROEJA e o PCC estão alinhados na mesma perspectiva crítica de reconhecimento das singularidades das comunidades e de valorização da diversidade e da equidade. A redução das diferenças sociais é uma tarefa da EA que se encontra presente nos documentos analisados quando enfatizam o papel da educação na promoção da cidadania e na universalização das oportunidades. Neste sentido, esta consonância significa um avanço importante em relação às demais políticas educacionais tanto para jovens e adultos como para o ensino profissionalizante.

Também é bem presente nas políticas atuais o sentimento de que abordagens anteriores não foram capazes de resolver o problema daqueles jovens e adultos que foram de algum modo excluídos do ensino regular. A inserção no mundo do trabalho via educação busca de certo modo romper com a lacuna histórica entre trabalho intelectual e trabalho manual, a profissionalização é oportunizada não como uma solução para os desfavorecidos, mas como uma forma de ruptura com o ciclo de exclusão Revbea, São Paulo, V. 10, Nº 1: 257-280, 2015. 
escolar. Um novo modelo de educação, não mais estigmatizante, mas inclusivo e apoiado em práticas mais dialógicas e contextualizadas, norteia tanto o PNEA como os demais documentos. Isto dito acerca da análise de políticas e documentos nos resta ainda compreender como pensam os docentes do curso acerca das concepções de EA que tratamos até então.

Os docentes do curso pesquisado têm graduações e especializações lato e stricto sensu bem variadas, voltadas para o universo da informática, apenas dois professores realizaram formação em áreas que envolvem o meio ambiente. Em seguida, buscamos saber se havia uma preocupação com o ambiente em que vive e quais eram suas atitudes cotidianas para cuidar do mesmo. Como era de se esperar todos os questionados responderam que se importam com o meio ambiente. Foi então realizada a categorização das atitudes citadas como importantes para a preservação do ambiente. As duas grandes preocupações giram em torno na reciclagem e do descarte correto dos resíduos sólidos, seguida do uso correto da água como medida de economia deste recurso.

Como vimos anteriormente, Reigota (1995) discrimina estas representações sociais dos temas ambientais em naturalista, globalizante e antropocêntrica. Diante das respostas dos participantes, ficou evidente que a maioria do corpo docente, em um total de 10, possui uma visão globalizante na qual o meio ambiente é integrado pela natureza e sociedade, dois professores compartilham a visão naturalista na qual o meio ambiente aparece como sinônimo de natureza intocada, caracterizando-se tipicamente pelos seus aspectos naturais e da qual o homem não faz parte e apenas um docente considera o meio ambiente em uma visão antropocêntrica, na qual ele é fonte dos recursos necessários para sobrevivência do ser humano. Citamos a seguir algumas definições extraídas das entrevistas e que demonstram a predominância da concepção globalizante de meio ambiente.

Meio Ambiente é tudo que faz a fauna e a flora viver no seu habitat (Participante 1).

Como atuo nas áreas das Ciências Biológicas, Ambiental e da Segurança do Trabalho, costumo conceituar o meio ambiente em três vertentes. O meio ambiente natural ou físico (flora, fauna, mares, rios, ar atmosférico, etc.); o meio ambiente artificial, que compreende o espaço urbano fechado (edificações) e o espaço urbano aberto (espaços livres em geral, como, por exemplo, praças, ruas, etc.). Desta forma, conceituamos o Meio Ambiente, como a interação do conjunto de elementos naturais, artificiais e culturais que propiciem $o$ desenvolvimento equilibrado da vida em todas as suas formas (Participante 2).

O meio em que vivemos (Participante 3 ). 
Concebo Meio Ambiente como a interação do homem com o ambiente que o cerca (nos aspectos biológicos, físicos, químicos) (Participante 4).

Todo o espaço onde vivemos (Participante 5).

Espaço do qual fazemos parte (Participante 6).

É todo espaço do planeta habitado (Participante 7).

Ambiente em qual vivemos (Participante 8).

Espaço onde a vida coexiste (Participante 9).

Local que o homem está inserido e que realiza todas as modificações (Participante 10).

Lugar de preservação, de uma natureza perfeita (Participante 11).

O ambiente no qual estamos inseridos, e como a relação humana interfere neste meio e nos outros adjacentes (Participante 12).

É todo espaço onde a vida se faz presente (Participante 13).

Procuramos saber se o educador está inserido em alguma pesquisa envolvendo o meio ambiente, no sentido de verificar a proximidade do mesmo em relação ao tema pesquisado e constatamos que apenas uma pequena parcela se encontra envolvida em investigações de cunho ambiental. Dos treze participantes apenas quatro estão inseridos em pesquisas que envolvem 0 meio ambiente, como descritos nos depoimentos abaixo:

Tenho um projeto apresentado a Coordenação de Meio Ambiente do IFBA no Campus de Vitória da Conquista, objetivando a implantação do viveiro de mudas de árvores que possam ser utilizadas nas áreas urbanas, tanto da sede do município, como na zona rural. Este projeto objetiva a melhoria e o aumento da área verde do município de Vitória da Conquista, adequando ao que é recomendado cientificamente (Participante 2).

Reuso e destinação correta de REEE (Participante 5).

Uso de energias renováveis, especificamente na área de energia solar (Participante 10).

Fontes alternativas de energia (eólica, biodigestores, etc.) (Participante 12).

Buscamos também levantar junto ao corpo docente seus conhecimentos prévios sobre o PROEJA e a PNEA, bem como acerca de sua aplicação na prática docente. Constatamos que apenas três professores declararam 
conhecer a PNEA. Complementando a pergunta acima, foi solicitado aos docentes que discorressem sobre seus conhecimentos sobre a PNEA. Os docentes que já tinham ciência da lei descreveram o seu conhecimento e os docentes que não tinham conhecimento da mesma informaram o que imaginavam ser. Dos treze investigados, apenas seis responderam a pergunta no questionário, nos fornecendo as seguintes descrições:

A Lei define o que seja a Educação Ambiental e os processos por meio dos quais o indivíduo e a coletividade constroem valores sociais, conhecimentos, habilidades, atitudes $e$ competências voltadas para a conservação do meio ambiente, bem de uso comum do povo, essencial à sadia qualidade de vida e sua sustentabilidade (Participante 2 ).

Imagino que seja um plano estabelecendo políticas e diretrizes para tratar da questão ambiental nos currículos escolares (Participante 3).

Penso que seja uma lei que esteja inserida no contexto da vida com sustentabilidade, cabendo a educação o papel de conscientizar as pessoas para uma vida harmoniosa com a natureza (Participante 4).

Programa de políticas e ensino ambientais (Participante 6).

Realmente desconhecia a lei. No entanto, tinha conhecimento que todas as disciplinas têm responsabilidade em trabalhar com o tema Meio Ambiente (Participante 7).

A inserção dos conhecimentos na interdisciplinaridade das matrizes curriculares dos cursos (Participante 12).

Todos os docentes afirmaram considerar relevante abordar o tema meio ambiente em sala de aula. Quando foram analisadas as razões que justificam esta importância, a maioria considera que o objetivo da EA é a tomada de consciência, ou seja, auxiliar as pessoas e os grupos sociais a adquirirem maior sensibilidade acerca do meio ambiente e dos seus problemas. Desse modo o professor contribui para que os estudantes possam adquirir uma compreensão básica do ambiente em sua totalidade, dos problemas a ele associados e do impacto das atividades humanas, promovendo neles um senso crítico de responsabilidade. A EA, segundo os docentes participantes, deve ajudar as pessoas e os grupos sociais a adquirir valores favoráveis ao meio ambiente que os impulsione a participar ativamente na sua proteção e melhoria.

Em seguida buscamos apreciar como estava sendo abordado o tema meio ambiente e quais eram as atividades que estavam sendo realizadas pelos docentes em sala de aula. Dos treze questionados apenas nove responderam dando a entender que os demais poderiam não estar trabalhando com o tema. As atividades mais citadas pelo docente pesquisado foram reciclagem e 
descarte adequado de lixo, seguida de trabalho de conscientização para a economia de energia e por último o plantio de árvores. Como se trata de um curso de informática não nos surpreende que o descarte e a reciclagem dos materiais eletrônicos seja a atividade de EA mais citada, já que a maioria das disciplinas são técnicas envolvendo a área direta da informática. O mesmo pode dizer dos temas referentes ao consumo de energia, que também acompanham a abordagem da TI Verde, tendência mundial voltada para 0 impacto dos recursos tecnológicos no meio ambiente. A preocupação dessa tendência está desde a utilização mais eficiente de energia, recursos e insumos na produção de tecnologia, até o uso de matéria prima e substâncias menos tóxicas na fabricação, priorizando recursos tecnológicos que consumam menos energia, que não agridam o meio ambiente na sua operação e que por fim minimize impactos no seu descarte, promovendo sua reciclagem e reutilização.

Para os participantes o principal locus de trabalho para a EA é justamente o espaço escolar, seguido de outros lugares como outros ambientes, áreas preservadas e comunidade local. Quanto ao método adotado pelos docentes, acompanhando a classificação de Reigota (1995) anteriormente descrita, encontramos que a maioria dos participantes manifesta preferência por estratégias da modalidade ativa, na qual os alunos realizam experiências sobre determinado tema, seguido da abordagem analítica, em que os alunos completam sua descrição com dados e informações e respondem a uma série de questões sobre o tema. O que verificamos é que alguns professores usam diversas metodologias durante o percurso educativo sendo a descritiva a menos empregada, na qual os alunos aprendem a definição de conceitos e descrevem o que eles observam.

Após analises detalhadas feitas nos documentos que envolvem e norteiam o curso de informática do PROEJA Campus de Vitória da Conquista nossa pesquisa chega à conclusão de que tanto o documento base do PROEJA, como o PPC do curso conseguem atender na sua grande maioria as exigências feitas pela PNEA, porém, no que tange a EA. Encontramos limitações quando analisamos as concepções de meio ambiente dos documentos. No quesito da concepção do meio ambiente propriamente dita 0 documento base do PROEJA está em alinhamento com a PNEA, porém o PPC apenas na ementa da disciplina de Segurança, Meio Ambiente e Saúde, trata a relação com a natureza, ainda assim em uma abordagem antropocêntrica, centrada na sua função de fornecedora de recursos para as pessoas.

Como vimos, ambos os documentos permitem a realização solicitada pela PNEA, de um ensino apoiado na interdisciplinaridade e transdisciplinaridade, deixando a multidisciplinaridade para organização da matriz curricular do curso. Assim, os alunos podem aprender variados conhecimentos de maneira simultânea tanto no plano teórico como prático. Se antes o alvo das políticas tanto da educação para jovens e adultos como para ensino profissionalizante era a compensação do que o seu público não possuía, atualmente temos a expectativa que, ao sair do PROEJA os estudantes estejam escolarmente tão aptos como os que cursaram o ensino 
médio regular, mas ainda mais preparadas para o mundo do trabalho. Um ponto importante tratado por ambos os documentos para atender a PNEA é o respeito à pluralidade e diversidade cultural do estudante, fazendo com que essas características sejam aproveitadas em sala como experiências ricas que veem a somar no processo educativo.

Porém, como assinalamos, o ponto negativo em que os o documentos deixam a desejar é o que trata das abordagens das questões que envolvem diretamente os ambientes naturais e os demais seres e processos vivos. Em nenhum momento os mesmos abrem um diálogo em relação ao assunto, ainda que não o obstaculizem. Em relação ao que foi exposto pelo corpo docente, percebemos se tratar de professores preparados, com no mínimo alguma especialização. Porém, poucas destas especializações se deram na área ambiental. Ainda assim, os educadores demonstraram possuir uma visão globalizante do meio ambiente, compactuando na sua grande maioria em uma preocupação constante sobre a preservação do mesmo, porém, com poucas práticas que reflitam no seu ambiente de trabalho e, por consequência na transformação do ser ambientalmente mais critico capaz de transformar seu meio, apesar da grande maioria informar que utilizam o espaço escolar para a Educação Ambiental e uma metodologia ativa onde permite os alunos fazerem experiências sobre o tema.

\section{Considerações finais}

Como vimos, a EJA no decorrer da nossa história ficou marcada por politicas públicas descontinuadas. Os jovens e adultos, no inicio da formalização do ensino no Brasil com a educação profissional, foram indivíduos desvalidos como escravos, órfãos e mendigos ou sujeitos a uma educação subalterna e subserviente. Foi apenas após a reforma Capanema em 1937, que o ensino profissional se uniu ao ensino médio e o ingresso às escolas exigiam exames admissionais, hoje em dia, quase oitenta anos depois ainda percebemos semelhanças nas regras e no modelo estabelecido. O PROEJA é exatamente a junção de ambos, o ensino profissional unido ao ensino médio com a proposta de além de formar um cidadão para o mercado de trabalho, formar também um cidadão critico e atuante na sociedade. Também percebemos que a divisão entre trabalho manual e intelectual só pode ser superada por meio de uma educação plena, ambiental e desconstrutora das desigualdades sócias.

Com as demandas atuais e a preocupação gritante em relação ao meio ambiente a proposta das políticas públicas de educação profissionalizante não é mais apenas formar estudantes para atuar no mercado de trabalho, mas sim a de produzir um cidadão atuante na sua sociedade, atento ao meio em que vive, ciente de suas responsabilidades para com o mesmo, em todos os seus aspectos (naturais, políticos, econômicos, sociais, culturais, estéticos, entre outros). Esta preocupação com o meio ambiente, em sua concepção ecológica e holística, está parcialmente insinuada no curso de informática do PROEJA no 
IFBA - Campus de Vitória da Conquista, preferencialmente em disciplinas especificas como SMS (Segurança, Meio Ambiente e Saúde) e Biologia e deve ser ampliada.

Pudemos observar o quão peculiar é o público atendido pelo PROEJA no IFBA de Vitória da Conquista. Diferente dos demais alunos da instituição, que também cursam o ensino médio profissionalizante, o pessoal do PROEJA é formado por jovens e adultos com idades variadas, que foram alijados do processo regular de escolarização e que retornam às salas de aulas no intuito de possuir uma formação ou, ainda, de passar por uma "reciclagem", visando geralmente um melhor retorno ao mercado de trabalho formal ou informal, constituindo um público composto por pessoas das mais variadas classes sociais e graus cognitivos. Se por um lado este público tão peculiar parece demandar por estratégias de ensino especiais, por outro observamos seu grande potencial para a EA, dado que os conhecimentos construídos serão aplicados na esfera profissional dos estudantes, mas, sobretudo, podem ter impacto em seu ambiente familiar e seu circulo social mais amplo, o que reforça a importância em se estabelecer uma articulação entre o PNEA e o PROEJA.

Os alunos do PROEJA apresentam especificidades diferentes dos alunos do ensino médio regular, suas experiências de vida e suas particularidades devem ser respeitadas, assim como a metodologia utilizada no desenvolvimento e na abordagem dos conteúdos programáticos deve ser diferenciada, evidenciando a importância de vincular os conteúdos das disciplinas a sua realidade possibilitando que se percebam como parte da história.

Outra limitação a ser superada foi à falta de capacitação na área de Educação Ambiental, o que faz com que muitas vezes os professores que trabalham com essa modalidade diferenciada de ensino se sintam desorientados no sentido que como desenvolver projetos voltados à Educação Ambiental junto a um público tão heterogêneo.

Com base neste estudo sobre a aplicação da PNEA no PROEJA do campus de Vitória da Conquista - Bahia, percebemos que o curso de informática do PROEJA de Vitória da Conquista deve efetuar futuras revisões do PPC, adotando uma visão menos tecnicista e desse modo, atender a todas as solicitações da PNEA que são as de uma sociedade mais sustentável com uma visão do ser humano mais integrado ao meio ambiente, possibilitando formar alunos ambientalmente mais críticos e capazes de possibilitar transformações mais pontuais nas suas interações com o meio em que vive. Desejamos que nossa pesquisa possa atuar como provocador de discussão e mudança na direção de uma EA crítica e efetiva.

Neste sentido indicamos a necessidade de atualização das políticas de modo a contemplar uma concepção sistêmica e articulada de meio ambiente que contemple seus aspectos humanos e naturais. Acreditamos que uma abordagem ecológica articulada das questões locais, regionais, nacionais e 
globais pode contribuir para a formação de jovens e adultos profissionais capazes refletir criticamente e perceber as demandas necessárias do contexto à sua volta, não como mero expectador e sim como ser participante e ativo de um ambiente do qual ele faz parte juntamente com demais seres e processos vivos.

\section{Referências}

ARROYO, M. Formação de educadores de jovens e adultos. Belo Horizonte: Secretaria da Educação, 2006.

BRASIL. Constituição da República Federativa do Brasil. Brasília, DF, Senado, 1988.

BRASIL. Lei n. 9.394, de 20 de dezembro de 1996. Estabelece as diretrizes a bases da Educação Nacional. Diário Oficial da República Federativa do Brasil, Brasília, DF, v. 134, n. 248, seção I, p. 27834-27841, 23 dez. 1996.

BRASIL. Lei no 9795, de 27 de abril de 1999. Dispõe sobre a EA, institui a Política Nacional de Educação Ambiental e dá outras providências. Disponível em: <http://www.planalto.gov.br/ccivil/Leis/L9795.htm>. Acesso em: 26 ago. 2013.

BRASIL. Ministério da Educação. Documento Base - Programa Nacional de Integração da Educação Profissional com a Educação Básica na Modalidade de Educação de Jovens e Adultos - PROEJA. Brasília: SETEC, 2007.

BRASIL. Ministério da Educação. Portal do MEC. Brasília, DF: MEC, 2011. Disponível em: <http://portal.mec.gov.br/index.php?id=13175\&option=comcontent\&view=article $>$. Acesso em: 14 nov. 2013.

FONSECA, C.S. História do ensino industrial no Brasil. Rio de Janeiro: Composto e Impresso no Curso de Tipografia e Encadernação da Escola Técnica Nacional, 1961.

GONÇALVES E SÁ, K. A; PEREIRA, C. A.; MOURA, R.C.G. Relação entre a teoria e a prática da Educação Ambiental na EJA do SESC - Petrolina/PE. Revista de Educação, Ciências e Matemática, Campinas, v. 2, n. 1, p. 69-80, jan.- abr. 2012.

GREGÓRIO, A.; LISOVSKI, L.A. Educação Ambiental: concepções e práticas na educação de jovens e adultos de diferentes escolas do noroeste do Paraná. Campo Mourão-PR. 2011. 12p.

GUIMARÃES, J. et al. Educação Ambiental na educação de jovens e adultos (EJA). Pato Branco: Synergismus scyentifica UTFPR, 2009.

HADDAD, S. Por uma nova cultura de educação de jovens e adultos: um balanço de experiências de poder local. In: HADDAD, S. et al. Novos Caminhos em Educação de Jovens e Adultos - EJA: um estudo de ações do poder público em cidades de regiões metropolitanas brasileiras. 1. ed. São Paulo: Global, 2007. p. 7-49. 
HADDAD, S.; DI PIERRO, M. C. Escolarização de jovens e adultos. Revista Brasileira de Educação, Campinas, n. 14, p.108-130, maio/ago. 2000.

IBGE. Pesquisa Nacional por Amostra de Domicílios, 2013. Disponível em ftp://ftp.ibge.gov.br/Trabalho e Rendimento/Pesquisa Nacional por Amostra de Domicilios continua/Fasciculos Indicadores IBGE/pnadc 201304 trimest re caderno.pdf. Acesso em 02 jul. 2014.

PRADO JR., C. Formação do Brasil Contemporâneo. São Paulo: Companhia das Letras, 2011.

REIGOTA, M. Meio ambiente e representação social. São Paulo: Cortez, 1995.

REIGOTA, M. O que é Educação Ambiental? São Paulo: Brasiliense, 2006. 62 p. (Coleção Primeiros Passos, n. 292)

REZENDE, V.A. A dimensão ambiental na Educação de Jovens e Adultos: possibilidades e desafios. In: V COLÓQUIO INTERNACIONAL 'EDUCAÇÃO E CONTEMPORANEIDADE', 2011, São Cristóvão. Anais... São Cristóvão, 2011.

ROMANELLI, O.O. História da Educação no Brasil (1930/1973). Petrópolis: Vozes, 1980.

SALDAÑA, P. Institutos federais têm déficit de $8 \mathrm{mil}$ professores, revela auditoria do TCU. São Paulo: Estadão, 2013. Disponível em: $<$ http://www.estadao-.com.br/noticias/impresso, institutos-federais-tem-deficitde-8-mil-professores-revela-auditoria-do-tcu,1013269,0.htm>. Acesso em: 15 jan. 2014.

SOUZA, G.L.R.; OLIVEIRA, T.M.. Educação Ambiental e Educação de Jovens Adultos: Reflexões para um Currículo Interdisciplinar. In: X MOSTRA ACADÊMICA E X CONGRESSO DE PÓS-GRADUAÇÃO, 2012, Piracicaba. Anais... Piracicaba, 2012. 